\title{
Improve the performance of orthogonal ASK/DPSK optical label switching by DC- balanced line encoding
}

Chi, Nan; Xu, Lin; Zhang, J.; Holm-Nielsen, Pablo Villanueva; Peucheret, Christophe; Yu, S.; Jeppesen, Palle

Published in:

Journal of Lightwave Technology

Link to article, DOI:

$10.1109 / \mathrm{JLT} .2005 .863274$

Publication date:

2006

Document Version

Publisher's PDF, also known as Version of record

Link back to DTU Orbit

Citation $(A P A)$ :

Chi, N., Xu, L., Zhang, J., Holm-Nielsen, P. V., Peucheret, C., Yu, S., \& Jeppesen, P. (2006). Improve the performance of orthogonal ASK/DPSK optical label switching by DC-balanced line encoding. Journal of Lightwave Technology, 24(3), 1082-1092. https://doi.org/10.1109/JLT.2005.863274

\section{General rights}

Copyright and moral rights for the publications made accessible in the public portal are retained by the authors and/or other copyright owners and it is a condition of accessing publications that users recognise and abide by the legal requirements associated with these rights.

- Users may download and print one copy of any publication from the public portal for the purpose of private study or research.

- You may not further distribute the material or use it for any profit-making activity or commercial gain

- You may freely distribute the URL identifying the publication in the public portal 


\title{
Improve the Performance of Orthogonal ASK/DPSK Optical Label Switching by DC-Balanced Line Encoding
}

\author{
Nan Chi, Member, IEEE, Lin Xu, Jianfeng Zhang, Member, IEEE, Pablo V. Holm-Nielsen, \\ Christophe Peucheret, Siyuan Yu, Member, IEEE, and Palle Jeppesen, Member, IEEE
}

\begin{abstract}
Orthogonal amplitude shift keying/differential phase-shift keying (ASK/DPSK) labeling is a promising approach to ultrahigh packet-rate routing and forwarding in the optical layer. However, the limitation on the payload extinction ratio (ER) is a detrimental effect for network scalability and transparency. This paper presents theoretical and experimental studies of ASK/ DPSK labeling. It proposes that dc-balanced 8B10B coding can greatly improve ER tolerance, which in turn leads to better system performance. By using the $8 \mathrm{~B} 10 \mathrm{~B}$ coding method, the paper demonstrates transmission and optical label swapping for a $40 \mathrm{~Gb} / \mathrm{s}$ ASK payload and a $2.5 \mathrm{~Gb} / \mathrm{s}$ DPSK label with an overall power penalty of $3.3 \mathrm{~dB}$ for the payload and $0.3 \mathrm{~dB}$ for the label. The experimental results also show that the ER is allowed to be as high as $12 \mathrm{~dB}$.
\end{abstract}

Index Terms-Amplitude shift keying, differential phase shift keying, optical label switching, orthogonal modulation.

\section{INTRODUCTION}

A LL-OPTICAL label switching is an important technique used to route and forward packets in future high-speed networks independently of IP packet length and payload bit rate [1]. Labels are received and swapped at every node in a core network, while payload information is transparently forwarded with possible wavelength conversion [2]. Several label-coding techniques have been reported, such as serial-bit labeling [4], subcarrier multiplexing [1]-[3], and orthogonal modulation labeling [5]-[17]. The orthogonal modulation technique encodes the label information on the optical carrier wave in a modulation format that is orthogonal to that of the payload, e.g., the label information is differential phase-shift keying (DPSK) modulated on the phase or frequency-shift keying (FSK) modulated on the optical frequency, while the payload is modulated on the

Manuscript received October 5, 2004; revised December 3, 2005. This work was performed at the IST Switching Technologies for Optically Labeled Signals (STOLAS) project supported in part by the European Commission.

N. Chi was with Research Center COM, Technical University of Denmark, Lyngby DK-2800, Denmark. She is now with the Department of Electrical and Electronic Engineering, University of Bristol, Bristol BS8 1TR, U.K. (e-mail: nan.chi@bristol.au.uk).

L. Xu, J. Zhang, P. V. Holm-Nielsen, C. Peucheret, and P. Jeppesen are with Research Center COM, Technical University of Denmark, Lyngby DK-2800, Denmark.

S. Yu is with the Department of Electrical and Electronic Engineering, University of Bristol, Bristol BS8 1TR, U.K.

Digital Object Identifier 10.1109/JLT.2005.863274 amplitude of the carrier; such methods are termed amplitude shift keying (ASK)/DPSK [7]-[10] and ASK/FSK [11], [12] labeling. Alternatively, the orthogonal label modulation format can be ASK superimposed on a payload with DPSK or FSK modulation [13]-[17]. The feasibility of orthogonal modulation labeling has been successfully demonstrated for all-optical label swapping and packet transmission [7]-[17]. Due to the compact spectrum, simple label swapping, and remarkable scalability to high bit rates, orthogonal modulation labeling is regarded as a competing scheme to subcarrier-multiplexed optical labeling.

A major performance limitation of orthogonal labeling comes from the crosstalk between the two modulation formats induced by the simultaneous amplitude and phase/frequency modulation on the same optical carrier [7]. The receiver sensitivity of the ASK signal improves as the ASK extinction ratio (ER) is increased, while the sensitivity of the DPSK or FSK signal deteriorates due to the reduced signal power when an ASK " 0 " is transmitted. Thus, the ASK ER has to be smaller than a certain value in order to correctly detect the information in the phase or frequency modulation [8], [16]. This requirement on the ASK ER limits the network scalability and the system transparency to signal format. However, the need to use a poor ER can be completely eliminated by utilizing special line coding on the ASK signal [18]-[21]. In principle, these coding methods can be divided into two categories, i.e., spectrum shaping by dc-balanced coding such as Manchester coding [11], [18] and 8B10B coding [19], [20], and use of temporal interleaved DPSK label [21]. These coding methods have been mainly applied to ASK/FSK and ASK/ASK labeling. So far, research on ASK/DPSK labeling has been limited to a maximum packet rate of $10 \mathrm{~Gb} / \mathrm{s}$ [9], [10], [21].

In this paper, we analyze the potential use of the ASK/DPSK labeling scheme with a packet rate of $40 \mathrm{~Gb} / \mathrm{s}$ without sacrificing payload ER. We demonstrate our latest experiment on ASK/DPSK signal transmission and label swapping for an ASK payload at $40 \mathrm{~Gb} / \mathrm{s}$ base rate with up to $12 \mathrm{~dB}$ ER. The experimental results show that by employing dc-balanced $8 \mathrm{~B} 10 \mathrm{~B}$ coding the tolerable payload ER can be greatly increased, which ultimately results in large improvement in payload and label sensitivities. This improvement in ER ensures network scalability, capacity upgrade, and transparent operation for the payload during all-optical wavelength conversion and $2 \mathrm{R} / 3 \mathrm{R}$ regeneration. 


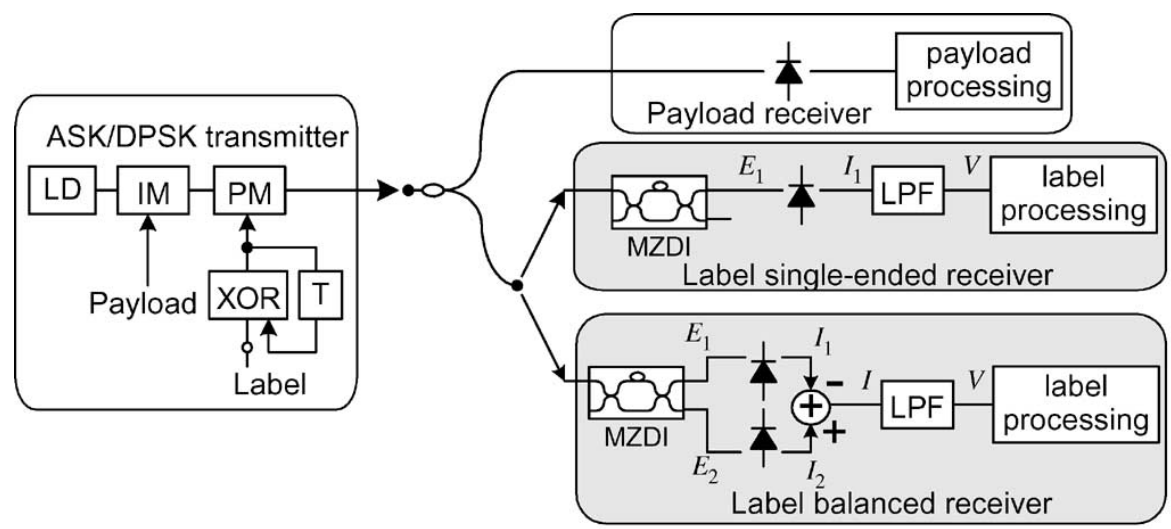

Fig. 1. Configuration of the optical ASK/DPSK transmitter and receiver.

The paper is organized as follows. A theoretical analysis on the performance of ASK/DPSK labeling without any coding method is presented for various DPSK label bit rates in Section II. In Section III, the performances of an 8B10B-coded ASK/DPSK signal simulated experimentally are demonstrated for a ASK payload at $40 \mathrm{~Gb} / \mathrm{s}$ and a DPSK label at $2.5 \mathrm{~Gb} / \mathrm{s}$ and $622 \mathrm{Mb} / \mathrm{s}$. The demonstration of $40 \mathrm{~Gb} / \mathrm{s}$ transmission and optical label swapping of ASK/DPSK labeling is described in Section IV. The paper is concluded in Section V.

\section{ERror Probability AND ReQUiRement ON ER}

In this section, an analysis of the error probability of an ASK/DPSK-labeled signal is presented when varying the payload and label bit rate. Based on this analysis, the requirement on the ASK ER is obtained. Fig. 1 shows the configuration of the transmitter and receiver of the ASK/DPSK labeling scheme. The laser source is intensity modulated to generate the ASK payload. The DPSK label is impressed by the subsequent phase modulator driven by the electrical precoded label signal. At the receiver, the labeled signal is split using a 3-dB optical coupler. The output of one arm is directly detected by a photodiode and thus the optical payload is converted into the electrical domain. From the second output of the coupler, the DPSK label is either directly detected by a Mach-Zehnder delay interferometer (MZDI) followed by a photodiode connected to one of the output ports, thus forming a single-ended receiver, or detected by a dual detector receiver connected to both output ports, forming a balanced receiver (see Fig. 1). The MZDI has a relative time delay between its two arms equal to the label bit period $T$.

The electrical field before the MZDI is

$$
E_{i n}(t)=\sqrt{P} A(t) \exp \left\{j\left[\omega_{\mathrm{c}} t+\phi(t)\right]\right\}
$$

where $P$ is the average optical power and $\omega_{\mathrm{c}}$ is the optical carrier angular frequency. $A(t)$ stands for the modulated amplitude containing the payload data and $\phi(t)$ is the modulating phase transmitted during the interval $(i-1) T<t \leq i T \quad(i=0$, $\pm 1, \pm 2, \ldots)$ corresponding to the label information. Assuming the coupling ratio of the two couplers in the MZDI is exactly
$3 \mathrm{~dB}$, the output electrical fields of the MZDI $E_{1}(t)$ and $E_{2}(t)$ can be obtained by the transformation

$$
\left[\begin{array}{l}
E_{1}(t) \\
E_{2}(t)
\end{array}\right]=\left[\begin{array}{cc}
0.5 & 0.5 e^{j \pi} \\
0.5 e^{\frac{j \pi}{2}} & 0.5 e^{\frac{j \pi}{2}}
\end{array}\right]\left[\begin{array}{c}
E_{i n}(t-T) \\
E_{i n}(t)
\end{array}\right] .
$$

\section{A. Single-Ended Receiver}

Denoting the responsivity of the photodiode $R$, the electrical current of the single-ended receiver after the photodiode is

$$
\begin{aligned}
I_{1}(t) & =R\left|E_{1}(t)\right|^{2} \\
& =\frac{1}{4} R P\left[A(t-T)^{2}+A(t)^{2}-2 A(t-T) A(t) \cos \Delta \phi\right]
\end{aligned}
$$

where $\Delta \phi=\phi(t)-\phi(t-T)$ is the phase shift between two neighboring label bits. For simplicity, we assume that the payload and label are synchronized and the payload bit rate divided by the label bit rate is an integer $N$. Thus, the payload duration is $\tau=T / N$. If the payload and label both have a square pulse shape, we have $\phi(t) \in\{0, \pi\}$ and

$$
A(t)=\sum_{i} A_{i} u_{\tau}(t-i \tau)
$$

where $u_{\tau}(t)$ is a unit amplitude rectangular pulse of duration $\tau$, $A_{i}=1$ represents the payload bit " 1 ," and $A_{i}=\sqrt{\varepsilon}(\varepsilon<1)$ for the payload bit " 0. ." Then, the payload ER is given by $-10 \log _{10} \varepsilon$. Fig. 2 gives examples of the initial and demodulated waveforms of an ASK/DPSK signal, where the label bit rate is half of the payload bit rate. Here, we consider an input ER of the payload that is equal to 6 and $100 \mathrm{~dB}$. The former is used to show the case when a limited ER is applied while the latter approximately shows the infinite ER case. In both cases, the demodulated DPSK label presents a multilevel structure due to the different possibilities of combination for the payload data and label data. When the input ER is equal to $6 \mathrm{~dB}$, proper DPSK detection can be achieved by carefully selecting the threshold. However, for the ASK/DPSK signal with an ER of $100 \mathrm{~dB}$, errors will always appear when two continuous payload "0"s are transmitted no matter how the threshold is adjusted. 


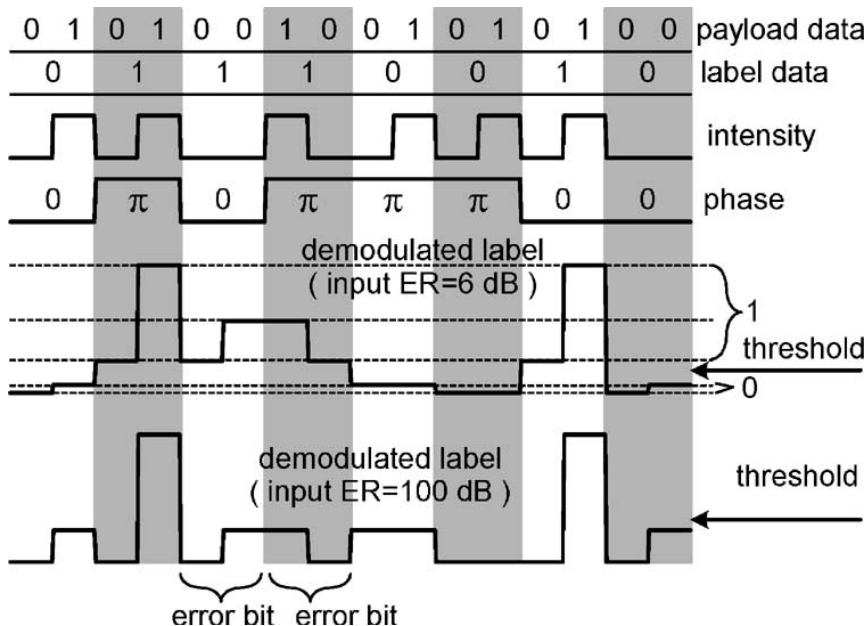

Fig. 2. Examples of ASK/DPSK labeling waveforms.

TABLE I

Power LeVels of $X_{i}$ Due to ASK Pulse Interference WHEN A SINGLE-ENDED RECEIVER IS APPLIED

\begin{tabular}{c|c|c|c}
\hline \multicolumn{2}{l|}{ Payload bit } & \multicolumn{2}{c}{$X_{i}$} \\
\hline$i$ & $i-N$ & Label bit '1' $(\Delta \phi=\pi)$ & Label bit '0' $(\Delta \phi=0)$ \\
\hline 1 & 1 & 1 & 0 \\
\hline 1 & 0 & $(1+\sqrt{\varepsilon})^{2} / 4$ & $(1-\sqrt{\varepsilon})^{2} / 4$ \\
\hline 0 & 1 & $(1+\sqrt{\varepsilon})^{2} / 4$ & $(1-\sqrt{\varepsilon})^{2} / 4$ \\
\hline 0 & 0 & $\varepsilon$ & 0 \\
\hline
\end{tabular}

Usually, a low-pass filter (LPF) is used after the photodiode in the DPSK label receiver. We specify the postdetection LPF to be a finite-time integrator with integration time $T$ [22]. If the receiver transimpedance is $Z_{0}$, the output voltage from the filter at decision time $T$ can be written as

$$
\begin{aligned}
V & =\frac{\int_{0}^{T} I_{1}(t) Z_{0} d t}{T} \\
& =\frac{Z_{0} R P}{4 T} \sum_{i=1}^{N}\left(A_{i}^{2}+A_{i-N}^{2}-2 A_{i} A_{i-N} \cos \Delta \phi\right) \frac{T}{N} \\
& =\frac{Z_{0} R P}{4 N} \sum_{i=1}^{N}\left(A_{i}^{2}+A_{i-N}^{2}-2 A_{i} A_{i-N} \cos \Delta \phi\right) .
\end{aligned}
$$

It is worth noting that in each DPSK label bit time $N$ ASK bits of one arm overlap with their counterpart in the other arm. Because of the difference between payload rate and label rate, interference exists between payload $A_{i}$ and $A_{i-N}$, but not between two neighboring payload bits. We define

$$
X_{i}=\frac{\left(A_{i}^{2}+A_{i-N}^{2}-2 A_{i} A_{i-N} \cos \Delta \phi\right)}{4} .
$$

The corresponding values of $X_{i}$ are given in Table I.

When an infinite ER is considered $(\varepsilon=0)$, the possible values of $X_{i}$ are $(0,1 / 4,1)$ for a label bit " 1 " and the probabilities of these values are $25 \%, 50 \%$, and $25 \%$, respectively. For a label bit " 0 ," the possible values of $X_{i}$ are $(1 / 4,0)$ with equal probability of $50 \%$.

Substituting (6) into (5), the output voltage normalized relative to $Z_{0} R P$ can be written by

$$
V=\frac{1}{N} \sum_{i=1}^{N} X_{i} .
$$

Hence, the final output of $V$ is proportional to the sum of $N$ randomly selected $X_{i}$. We first consider the case when the label bit is "1." Assuming the numbers of $X_{i}=0, X_{i}=0.25$, and $X_{i}=1$ are $l, m$, and $n$, respectively, where $l+m+n=N$, (7) is given by

$$
\begin{aligned}
V & =\frac{1}{N}\left(l \cdot 0+m \cdot \frac{1}{4}+n \cdot 1\right) \\
& =\frac{m+4 n}{4 N}, \quad\left\{\begin{array}{l}
m+n \leq N \\
m, n=0,1, \ldots N
\end{array}\right.
\end{aligned}
$$

The corresponding probability is

$$
P_{1}=\left(\begin{array}{l}
N \\
m
\end{array}\right)\left(\begin{array}{c}
N-m \\
n
\end{array}\right) 0.25^{(N-m-n)} 0.5^{m} 0.25^{n} .
$$

The fact that $m+4 n=(m+4)+4(n-1)=\cdots=(m+$ $4 n)+4.0$ means that the following combinations of $(m, n)$ have the same output $V:(m+4, n-1),(m+2 \cdot 4, n-$ $2), \ldots$, and $(m+4 n, 0)$. The total probability of $V=(m+$ $4 n) / 4 N$ becomes

$$
\begin{aligned}
P_{1}= & \sum_{i=0}^{n}\left(\begin{array}{c}
N \\
m+4 i
\end{array}\right)\left(\begin{array}{c}
N-m-4 i \\
n-i
\end{array}\right) \\
& \times 0.25^{N-(m+4 i)-(n-i)} 0.5^{m+4 i} 0.25^{n-i} \\
= & \sum_{i=0}^{n}\left(\begin{array}{c}
N \\
m+4 i
\end{array}\right)\left(\begin{array}{c}
N-m-4 i \\
n-i
\end{array}\right) 2^{-2 N+m+4 i} .
\end{aligned}
$$

For a label bit " 0 ," assuming the numbers of $X_{i}=0$ and $X_{i}=$ 0.25 are $l$ and $m$, respectively, and $l+m=N$, the output voltage is

$$
V=\frac{1}{N}(l \cdot 0+m \cdot 0.25)=\frac{m}{4 N}, \quad m=0,1, \ldots, N .
$$

The probability of that is given by

$$
P_{0}=\left(\begin{array}{l}
N \\
m
\end{array}\right) 0.5^{l} 0.5^{m}=\left(\begin{array}{l}
N \\
m
\end{array}\right) 2^{-N} .
$$

In Fig. 3, the power level distributions are numerically studied for all the possibilities of payload combinations over two neighboring label bits when $N=3,4,7$, and 10 . Two neighboring label bits are equal to $2 N$ payload bits, corresponding to a number of binary payload combinations of $2^{2 N}$. The numerical results verify the expressions given in (10) and (12). Moreover, an optimum threshold is found to be around 0.2. Therefore, we set the threshold to 0.2 regardless of $N$ and we assume that the 

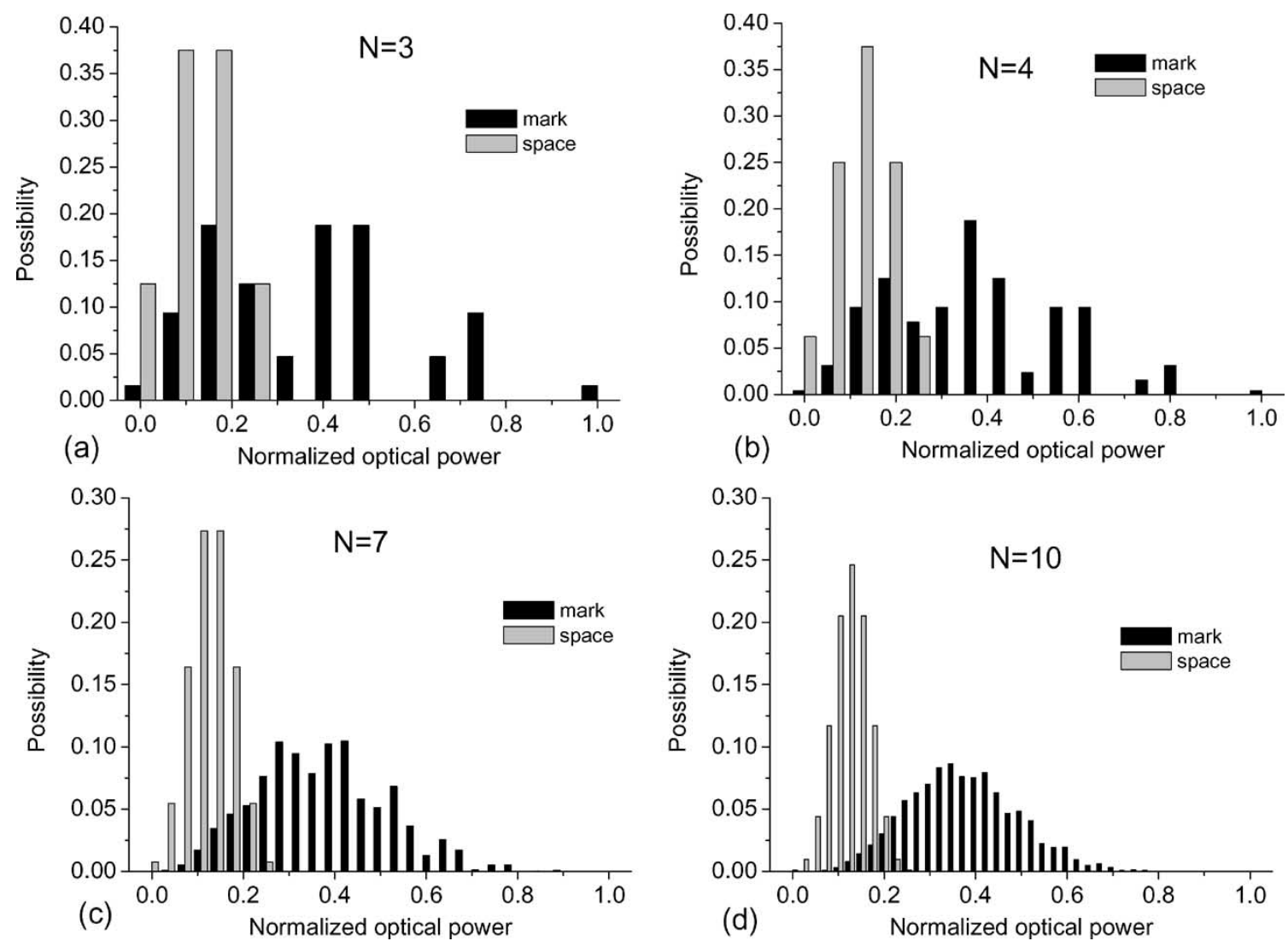

Fig. 3. Probabilities of occurrences of the different allowed label intensity levels for single-ended detection as a function of the payload to label bit rate ratio $N$.

"mark" and the "space" are equally likely to occur. Then the total error probability is obtained by

$$
\begin{array}{r}
P_{e}=\frac{1}{2}\left[2^{-N} \sum_{i=N+1-r}^{N}\left(\begin{array}{c}
N \\
i
\end{array}\right)+\sum_{m+4 n<r} \sum_{i=0}^{n}\left(\begin{array}{c}
N \\
m+4 i
\end{array}\right)\right. \\
\left.\times\left(\begin{array}{c}
N-m-4 i \\
n-i
\end{array}\right) 2^{-2 N+m+4 i}\right]
\end{array}
$$

where $r$ stands for the number of "mark" levels below the threshold. Fig. 4 presents the error probability as a function of $N$ when a single-ended receiver is used for DPSK detection. System performance shows an improvement with increasing values of $N$-the ratio between payload and label bit rate-which means the following.

- If the label bit rate is fixed, increasing the payload bit rate will improve DPSK detection. Hence, upgrading payload capacity will improve label performance.

- If the payload bit rate is fixed, a lower speed DPSK label has better performance and costly high-speed components for label detection and processing are avoided.

The simulation results based on VPI Transmission Maker 5.5 for the demodulated DPSK signal are shown in Fig. 5, where the payload is a $40 \mathrm{~Gb} / \mathrm{s} 2^{30}-1$ pseudorandom bit sequence (PRBS) and the label rates are $1 / 4,1 / 16,1 / 32$, and 1/64 of the payload rate. The bandwidth of the LPF is $70 \%$ of the label bit rate. The eye opening of the demodulated DPSK eye diagram tends to increase with an increasing value of $N$, supporting the above conclusion.

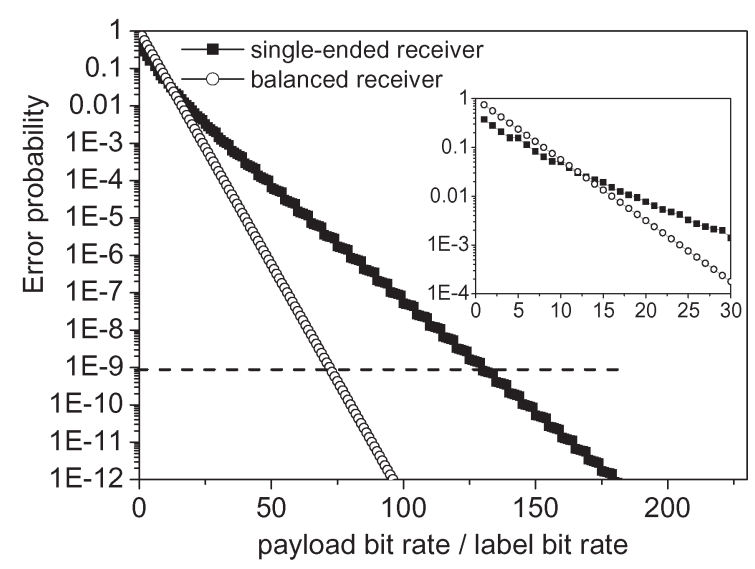

Fig. 4. Error probability of the DPSK label as a function of the ratio of payload and label bit rate.

Fig. 4 also shows that the error probability is less than $10^{-9}$ for $N>130$. For instance, if the payload bit rate is $40 \mathrm{~Gb} / \mathrm{s}$, the label bit rate should be lower than $307 \mathrm{Mb} / \mathrm{s}$ to ensure error-free operation. However, using the DPSK modulation format for the relatively low label bit rate will result in a strict requirement on the laser linewidth [9]. Moreover, the temperature and mechanical stabilization of the MZDI used for DPSK demodulation will become a challenge due to the large delay between the two arms. A DPSK label at $307 \mathrm{Mb} / \mathrm{s}$ corresponds to a delay of the order of $67 \mathrm{~cm}$ if the delay is implemented in conventional silica fiber. Such a long length difference will obviously be very difficult to accurately control 

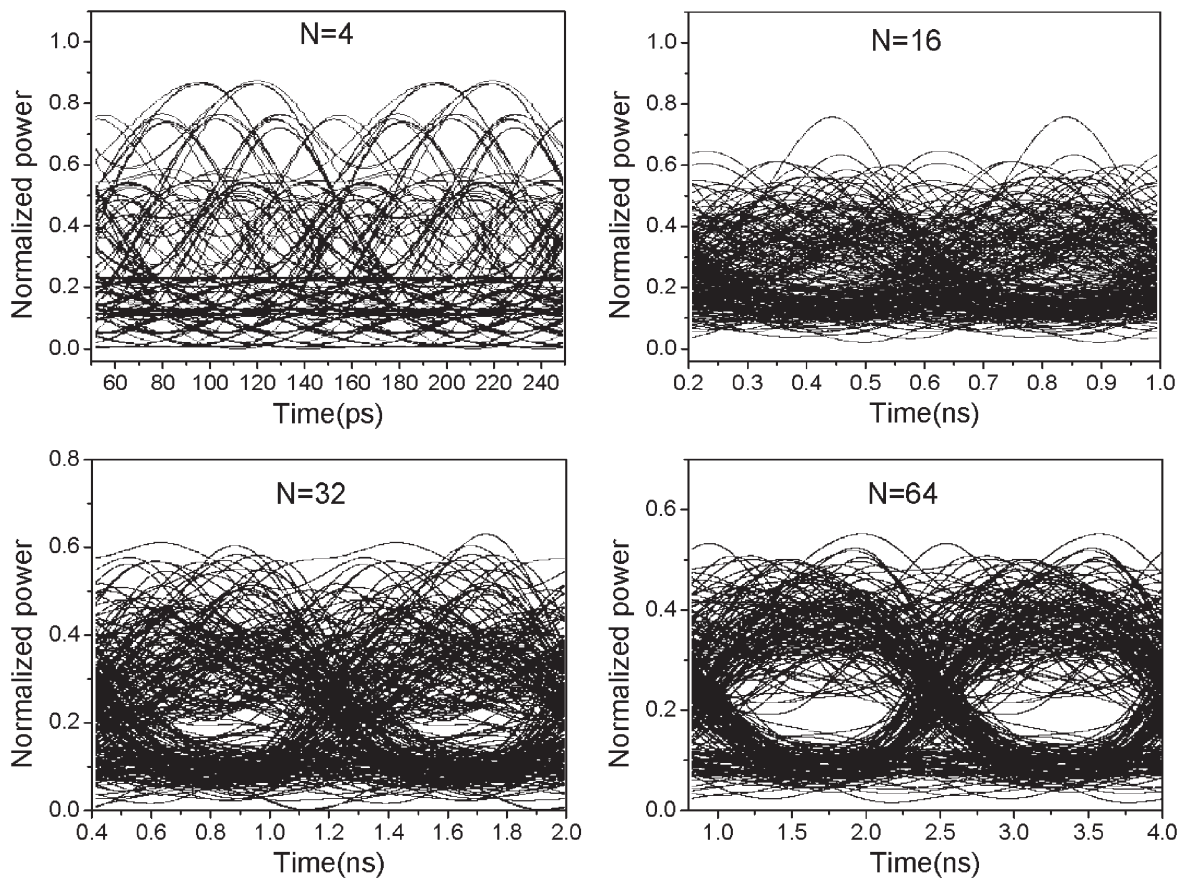

Fig. 5. Simulated eye diagrams of the demodulated DPSK label deploying a single-ended receiver.

and stabilize. Therefore, without special coding of the payload, the payload ER has to be sacrificed in case of single-ended detection.

\section{B. Balanced Receiver}

For the balanced receiver, the output electrical current can be written as

$$
I(t)=I_{2}(t)-I_{1}(t)=-R P A(t-T) A(t) \cos \Delta \phi .
$$

The output voltage normalized to $Z_{0} R P$ at sampling instant $T$ is

$$
\begin{aligned}
V & =\frac{\int_{0}^{T} I(t) Z_{0} d t}{Z_{0} R P T} \\
& =-\frac{1}{N} \sum_{i=1}^{N}\left(A_{i} A_{i-N} \cos \Delta \phi\right) \\
& =\frac{1}{N} \sum_{i=1}^{N} Y_{i}
\end{aligned}
$$

where $Y_{i}=-A_{i} A_{i-N} \cos \Delta \phi$. The possible values of $Y_{i}$ are shown in Table II.

When an infinite ER is considered $(\varepsilon=0)$, the possible values of $Y_{i}$ are $(0,1)$ for a label bit " 1 ," and the probabilities of these values are $75 \%$ and $25 \%$, respectively. Assuming the numbers of $Y_{i}=0$ and $Y_{i}=1$ are $m$ and $n$, respectively, and $m+n=N$, (15) can be written as

$$
V=\frac{n}{N}, \quad n=0,1, \ldots, N .
$$

TABLE II

POWER LEVEls of $Y_{i}$ DUe to ASK PULSE INTERFERENCE WHEN A BALANCED RECEIVER IS APPLIED

\begin{tabular}{c|c|c|c}
\hline \multicolumn{2}{c|}{ Payload bit } & \multicolumn{2}{|c}{$Y_{i}$} \\
\hline$i$ & $i-N$ & Label bit '1' $(\Delta \phi=\pi)$ & Label bit '0' $(\Delta \phi=0)$ \\
\hline 1 & 1 & 1 & -1 \\
\hline 1 & 0 & $\sqrt{\varepsilon}$ & $-\sqrt{\varepsilon}$ \\
\hline 0 & 1 & $\sqrt{\varepsilon}$ & $-\sqrt{\varepsilon}$ \\
\hline 0 & 0 & $\varepsilon$ & $-\varepsilon$ \\
\hline
\end{tabular}

The probability of that value is

$$
P_{1}=\left(\begin{array}{c}
N \\
n
\end{array}\right) 0.75^{m} 0.25^{n}=\left(\begin{array}{l}
N \\
n
\end{array}\right) \frac{3^{N-n}}{2^{2 N}} .
$$

For a label bit " 0 ," the possible values of $Y_{i}$ are $(-1,0)$ with probabilities of $25 \%$ and $75 \%$, respectively. Assuming that the numbers of $Y_{i}=0$ and $Y_{i}=-1$ are $m$ and $n$, respectively, and $m+n=N$, (15) can be written as

$$
V=-\frac{n}{N}, \quad n=0,1, \ldots, N .
$$

The probability of that value is

$$
P_{0}=\left(\begin{array}{c}
N \\
n
\end{array}\right) 0.75^{m} 0.25^{n}=\left(\begin{array}{l}
N \\
n
\end{array}\right) \frac{3^{N-n}}{2^{2 N}} .
$$

If we set the threshold at 0 so that $V<0$ represents a label bit "0" and $V>0$ a label bit "1," the errors occur when $V=0$. Thus, the error probability of the balanced receiver is achieved as

$$
P_{e}=\frac{1}{2}\left(\left.P_{1}\right|_{n=0}+\left.P_{0}\right|_{n=0}\right)=\frac{3^{N}}{2^{2 N}} .
$$



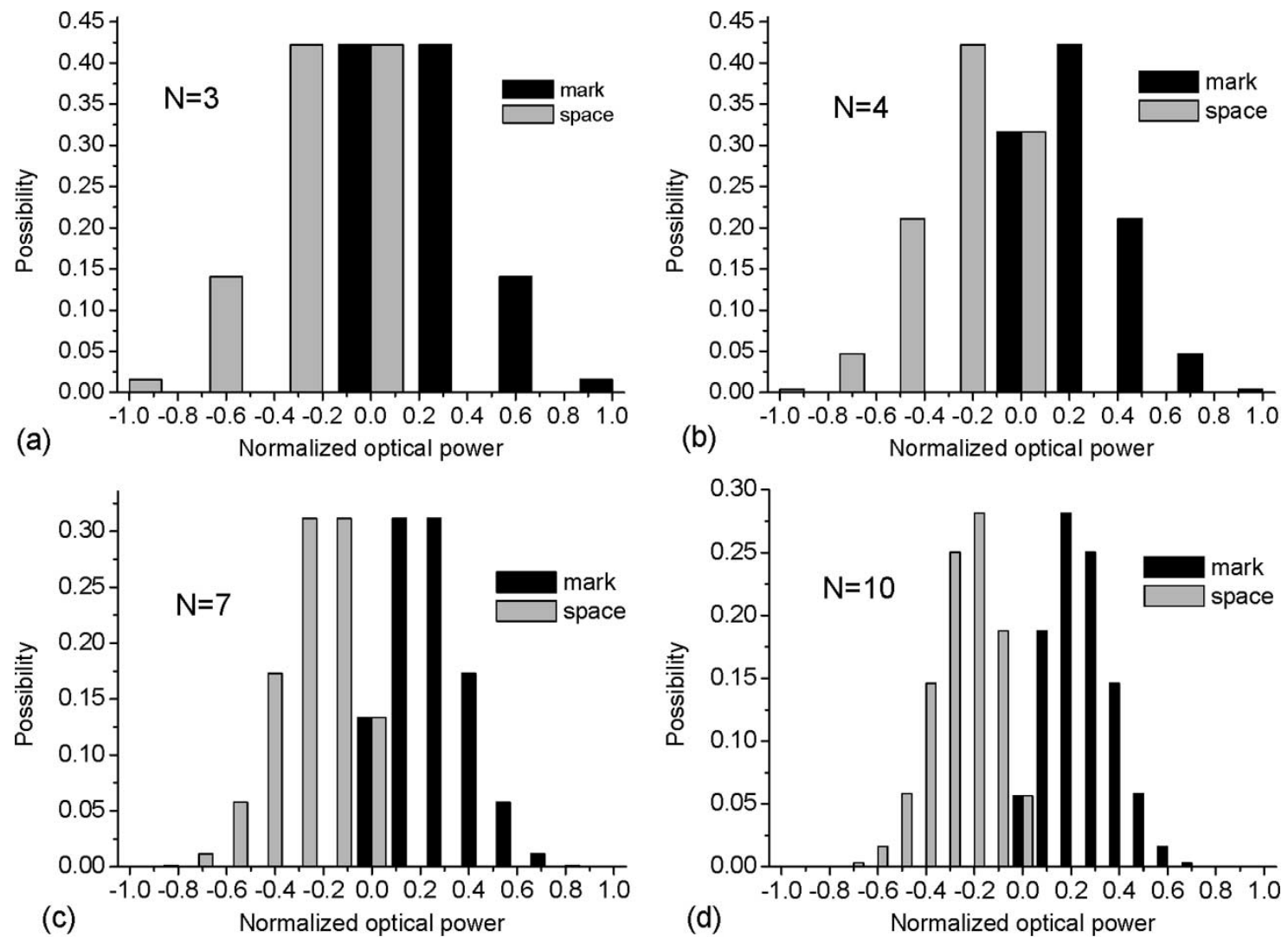

Fig. 6. Probability of the optical power levels for a balanced receiver after an LPF.
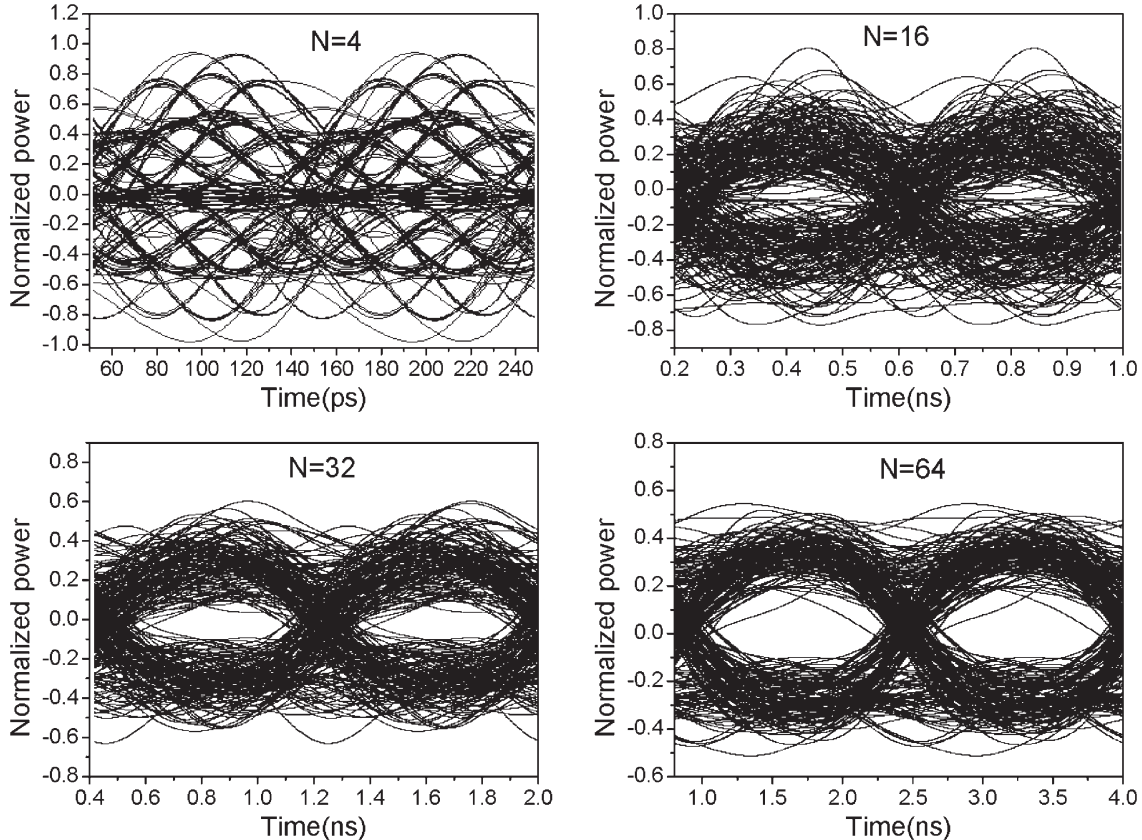

Fig. 7. Simulated eye diagrams of the demodulated DPSK label using a balanced receiver.

We evaluate (20) by numerically calculating all the possibilities of the payload combinations for $N=3,4,7$, and 10 , as shown in Fig. 6. The numerical results are in excellent agreement with the analytical results from (20). According to (20), Fig. 4 shows the error probability versus $N$ (ratio of payload and label bit rate) when a balanced receiver is applied. For $N>0$, the error probability is a monotonically decreasing function for increasing values of $N$, indicating that better performance can be achieved when the payload bit rate is much higher than the label bit rate. The simulation results based on VPI Transmission Maker 5.5 are shown in Fig. 7. Clearly, the eye opening is enhanced when a large $N$ is deployed. 
Fig. 4 compares the performance of the two types of receivers. For $N<13$, the single-ended receiver has better performance than the balanced receiver. However, the balanced receiver shows advantages at lower label bit rate when $N \geq 13$. If the payload is at $40 \mathrm{~Gb} / \mathrm{s}$, a balanced receiver is preferred for label bit rates lower than $3.07 \mathrm{~Gb} / \mathrm{s}$.

It is also found from Fig. 4 that for $N \geq 73, P_{\mathrm{e}}$ is less than $10^{-9}$. For a $40 \mathrm{~Gb} / \mathrm{s}$ payload, the label bit rate has to be lower than $550 \mathrm{Mb} / \mathrm{s}$ to get error-free operation, and such a bit rate requires an MZDI with a length difference larger than $37.6 \mathrm{~cm}$, still too long to get precise control and stabilization. Therefore, even with a balanced receiver, error-free DPSK detection cannot be achieved for a $40 \mathrm{~Gb} / \mathrm{s}$ payload with good ER.

\section{Requirement on the Payload ER}

If the payload ER is a finite value, (15) will never give 0 because $Y_{i} \neq 0$. Thus, there is no error by using a balanced receiver. We define the eye opening as the difference of the smallest "1" level and the largest "0" level. Based on our previous investigation in Table I, the eye opening for a singleended receiver is given by

$$
\mathrm{EOP}=\varepsilon-\frac{(1-\sqrt{\varepsilon})^{2}}{4} .
$$

To get an eye opening EOP $>0, \varepsilon$ should be larger than 1/9, corresponding to an $\mathrm{ER}\left(=-10 \log _{10} \varepsilon\right)$ less than $9.5 \mathrm{~dB}$. If the label receiver sensitivity is set to be around the same level as for the payload and noise is taken into consideration, the payload ER has to be further decreased to $3-4 \mathrm{~dB}$ as we examined in earlier experiments [9], [10]. Such low ER will obviously degrade system performance and give rise to problems for multihop scalability and all-optical processing of the payload such as $2 R / 3 R$ regeneration and wavelength conversion. Therefore, it is critical for use of ASK/DPSK labeling to find effective ways to enhance the payload ER while maintaining proper DPSK detection.

\section{8B10B Coding Method For the PAYloAd}

Several coding methods have been proposed to improve the system performance of optical labeling by reducing the modulation crosstalk between payload and label, including Manchester coding for ASK/FSK labeling [11], Manchester coding for subcarrier multiplexing labeling [18], 8B10B coding for ASK/FSK labeling [19], 8B10B for ASK/ASK labeling [20], and interleaved DPSK label for ASK/DPSK labeling [21].

An interleaved DPSK label [21] is better understood on the basis of time domain. Assuming the DPSK bit rate is $N$ times lower than the payload bit rate, a pair of "mark" bits are inserted for every $N+2$ payload bit frame. The DPSK label is synchronously modulated on the payload with the boundary of the label bit transition aligned with the middle of the pair of mark bits. To detect the DPSK label, an MZDI with a delay matching with the payload bit rate has to be used [21]. The bandwidth efficiency of the payload is $N /(N+2)$. However,

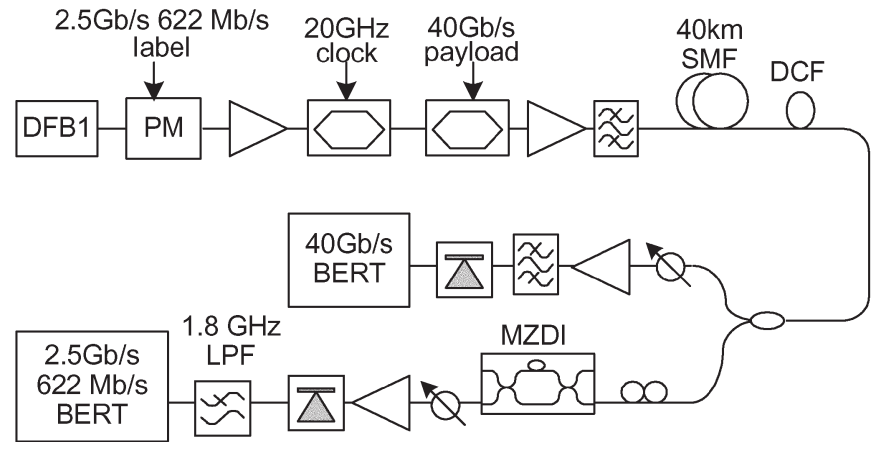

Fig. 8. Simulation and experimental setup for an ASK/DPSK-labeled signal.

this scheme requires precise synchronization and timing alignment between the interval of the payload "mark" pairs and the label boundary. Furthermore, it requires that the transition time (rising and falling edge) of the label bit be very small compared to the payload bit duration, which results in an extra bandwidth requirement on the label transmitter.

The advantage of Manchester coding and 8B10B coding can be understood on the basis of spectrum shaping. In the RF frequency domain, the crosstalk between payload and label is generated by the overlap of the payload spectrum with the label spectrum. Because the label bit rate is typically much lower than the payload bit rate due to the small amount of control information, the label signal is a narrow-band signal. If we shape the payload spectrum to have a null at $\mathrm{dc}$, the crosstalk will be suppressed significantly. Several line coding techniques can generate a dc-null spectrum, such as Manchester coding and 8B10B [23]. Manchester coding has advantages in clock recovery (CR) and burst-mode data reception; however, it doubles the bandwidth requirements on the payload transmitter and receiver so the bandwidth efficiency is halved. Therefore, we chose $8 \mathrm{~B} 10 \mathrm{~B}$ coding because of its popularity in an Ethernet environment and its relatively high bandwidth efficiency $(80 \%)$.

In order to compare the performance of the ASK/DPSKlabeled signal with or without line coding for the payload, simulations have been made with the VPI software. The system model of the ASK/DPSK link is shown in Fig. 8. The laser wavelength is taken to be $1550 \mathrm{~nm}$. The transmission span consists of $40 \mathrm{~km}$ of standard single mode fiber (SMF) with a matching length of dispersion compensating fiber (DCF) in a postcompensation scheme. The dispersion at $1550 \mathrm{~nm}$ of the SMF and DCF is 16.9 and $-100 \mathrm{ps} / \mathrm{nm} / \mathrm{km}$, respectively. An MZDI with single-bit delay in one arm is used for DPSK demodulation. It should be noted that the payload and the label are at different data rates and use different receivers; they may require different received powers. To obtain an optimum overall receiver sensitivity, the split ratio of the coupler in the receiver should be adjusted such that for the minimum received power both ASK and DPSK receivers operate at their sensitivity limits [6]. However, for simplicity, we assume that a 3-dB coupler is used at the receiver, yielding an optimum value of ER where the payload and label have the same receiver sensitivity; this dual operation requirement is coincident with previous research in [13] and [24]. 

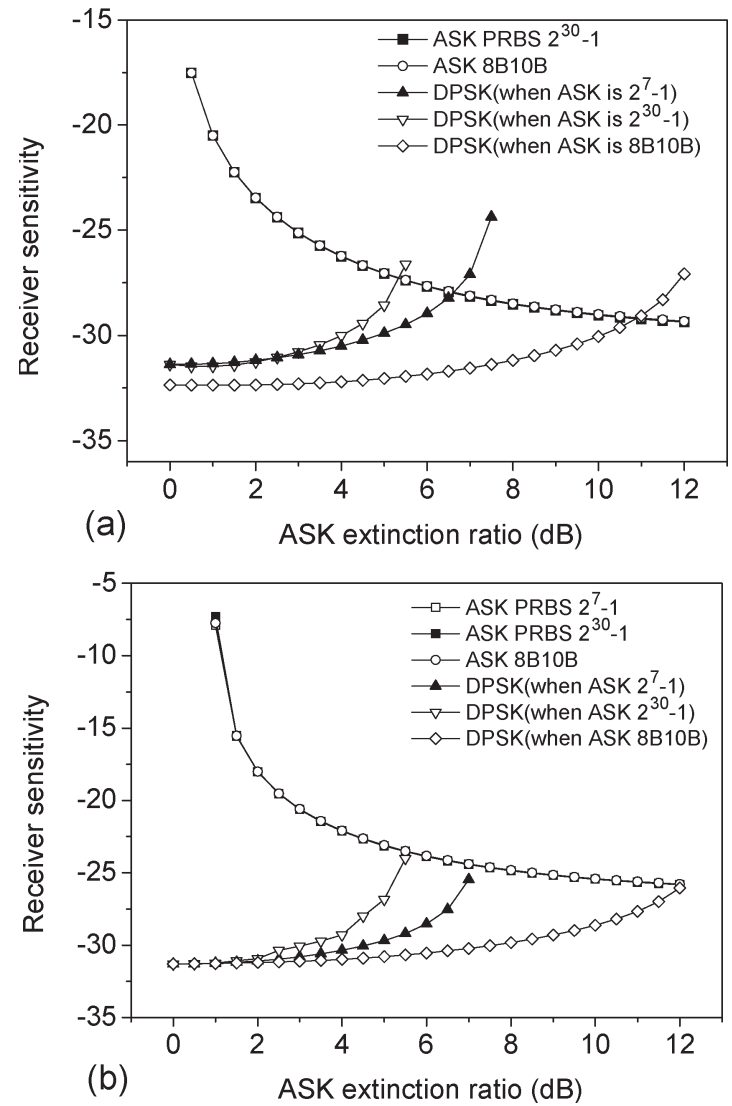

Fig. 9. Simulated receiver sensitivity for the $40 \mathrm{~Gb} / \mathrm{s}$ ASK payload and $2.5 \mathrm{~Gb} / \mathrm{s}$ DPSK label versus input ER of the payload. (a) Back to back case. (b) After transmission over 40-km SMF.

The calculated receiver sensitivity curves versus payload ER are shown in Fig. 9. It can be seen that the ASK/DPSK combined format can achieve a transmission distance of $40-\mathrm{km}$ SMF without any significant receiver sensitivity degradation. For a PRBS payload, the optimum ER is about 5-7 dB. A longer PRBS sequence requires lower ER of the payload. The optimum ER can be dramatically enhanced to around $11 \mathrm{~dB}$ as soon as the $8 \mathrm{~B} 10 \mathrm{~B}$ line coding is applied to the payload.

To verify the feasibility of the ASK/DPSK-labeled signal using 8B10B line coding, a back-to-back experiment was setup as shown in Fig. 8. The system performances of 8B10B coding are evaluated back-to-back for the ASK/DPSK signal, consisting of a payload at $40 \mathrm{~Gb} / \mathrm{s}$ and a label at $2.5 \mathrm{~Gb} / \mathrm{s}$ or $622 \mathrm{Mb} / \mathrm{s} .8 \mathrm{~B} 10 \mathrm{~B}$ coding is directly generated through encoding a $2^{7}-1$ PRBS by programming the data pattern generator, corresponding to a periodical data pattern of 160 bits. The DPSK demodulator has a delay of $8 \mathrm{~cm}$ corresponding to $400 \mathrm{ps}$. The label bit sequence is a $2^{23}-1$ PRBS.

The measured receiver sensitivities of the payload and the label as a function of the ER are shown in Fig. 10. The received eye diagrams of the DPSK label are shown in Fig. 11(a) and (b) for a label at $2.5 \mathrm{~Gb} / \mathrm{s}$ and in Fig. 11(c) and (d) at $622 \mathrm{Mb} / \mathrm{s}$. As expected, we observe a tradeoff between the ER requirements for the payload and label. A degraded ER is known to result in a penalty for the payload whereas an increase in the ER leads to a receiver penalty on the label. For a payload coded with a $2^{7}-1$ PRBS sequence, an optimum value of $7 \mathrm{~dB}$ ER is
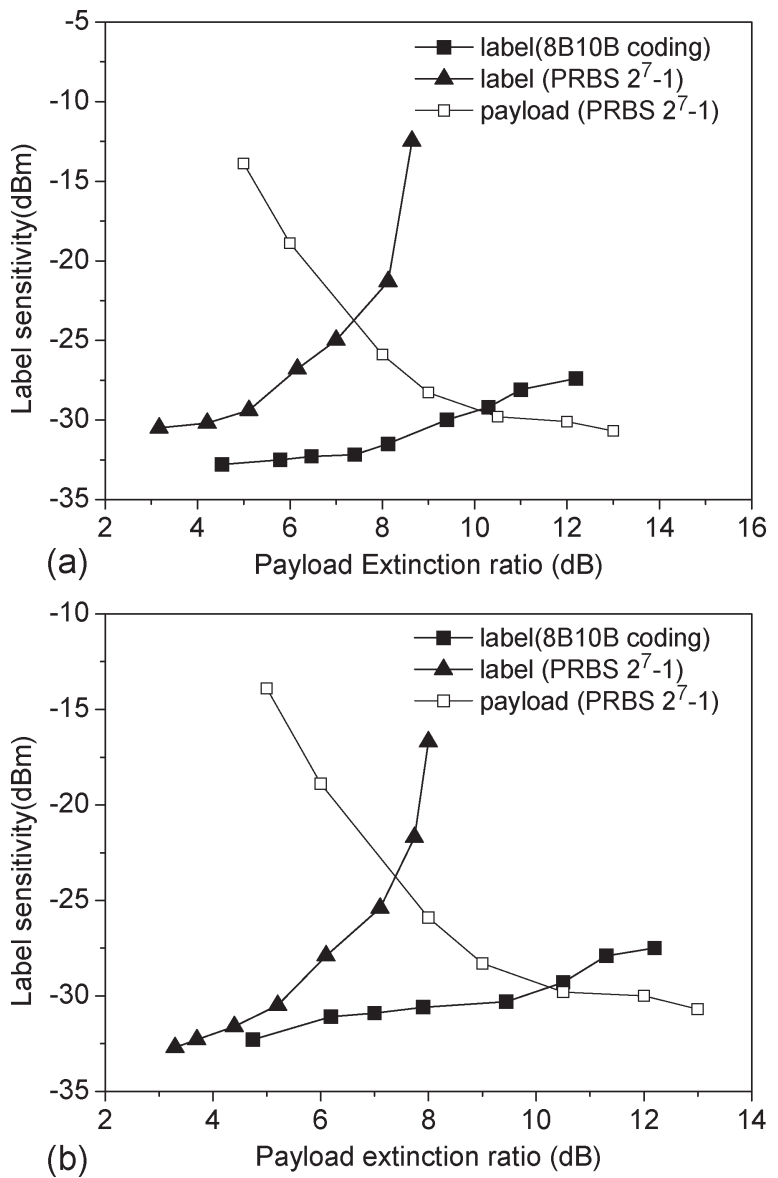

Fig. 10. Measured receiver sensitivity for the payload and label versus input ER of the payload. (a) Label at $2.5 \mathrm{~Gb} / \mathrm{s}$. (b) Label at $622 \mathrm{Mb} / \mathrm{s}$.

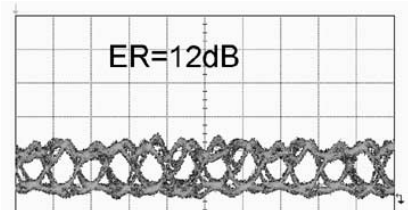

(a) 500ps/div

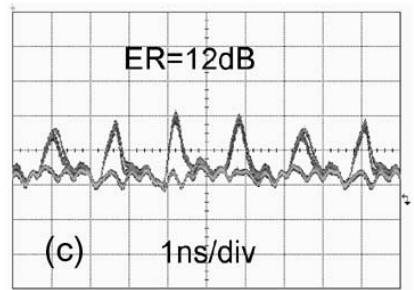

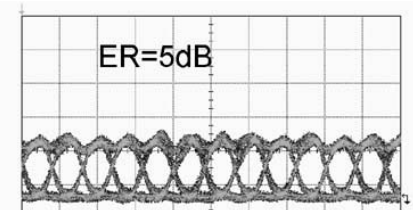

(b) 500ps/div

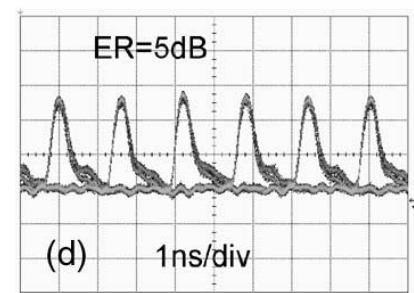

Fig. 11. Received DPSK label at $2.5 \mathrm{~Gb} / \mathrm{s}$ (a) and (b) with mark insertion coding (c) and (d) with 8B10B coding.

obtained, where the payload and label have the same sensitivity. It should be noted that this optimum value can be greatly decreased when a longer PRBS sequence is used for the payload due to the increased length of the continuous "marks" and "spaces." On the other hand, this optimum value is enhanced to $10 \mathrm{~dB}$ when $8 \mathrm{~B} 10 \mathrm{~B}$ coding is applied to the payload. It is also found that the DPSK receiver sensitivity will be greatly 


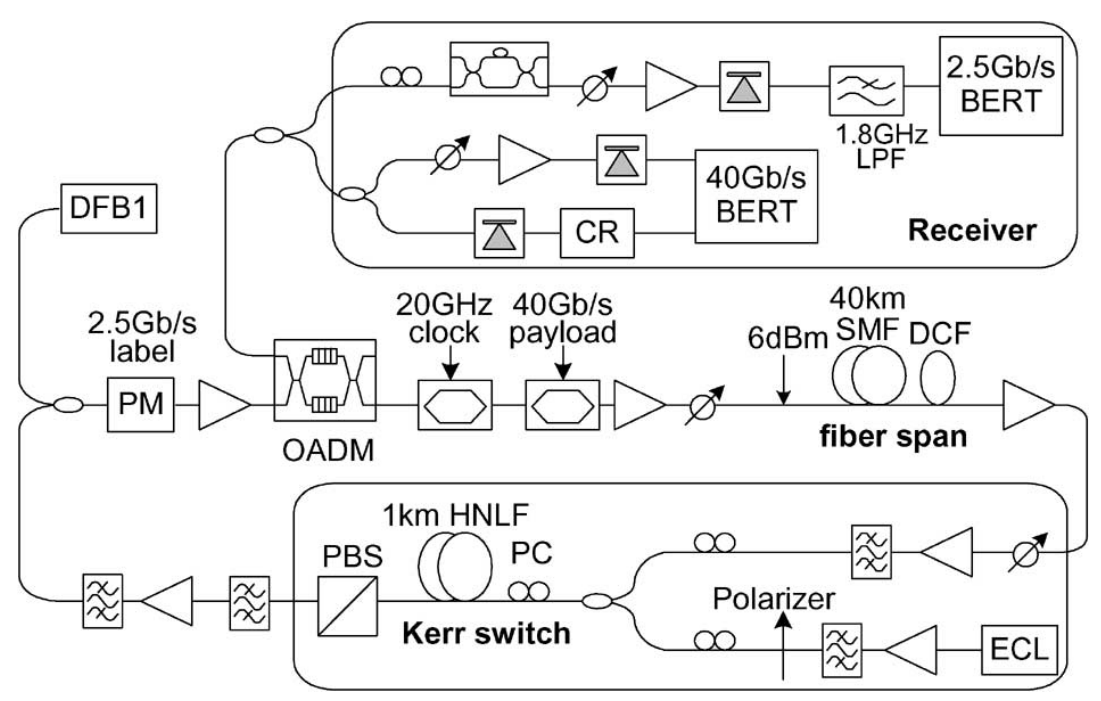

Fig. 12. Experimental setup for transmission and label swapping. PBS: polarization beam splitter, PC: polarization controller.

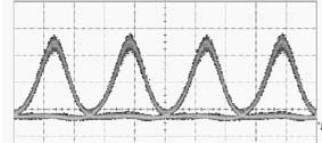

(a) $10 \mathrm{ps} / \mathrm{div}$

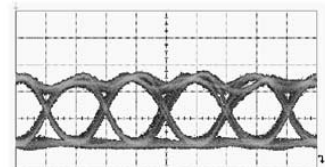

(d) $200 \mathrm{ps} / \mathrm{div}$

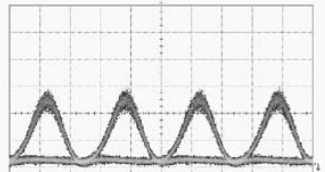

(b) $10 \mathrm{ps} / \mathrm{div}$

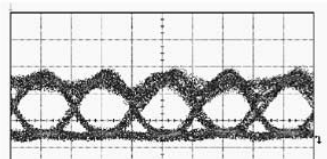

(e) $200 \mathrm{ps} / \mathrm{div}$
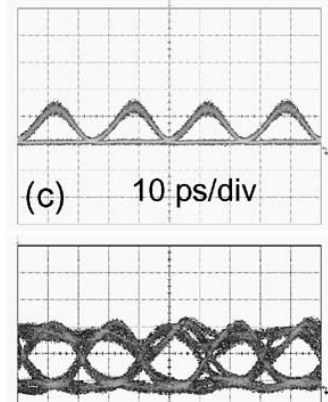

(f) $200 \mathrm{ps} / \mathrm{div}$

Fig. 13. Received eye diagrams for the $40 \mathrm{~Gb} / \mathrm{s}$ payload (above) and $2.5 \mathrm{~Gb} / \mathrm{s}$ label (below). (a) and (d) Back-to-back. (b) and (e) Transmission over $40-\mathrm{km}$ fiber. (c) and (f) Transmission and swapping.

enhanced at lower label rates. This conclusion is consistent with the theoretical results given in [19].

\section{TRANSMisSion AND LABEl SWAPPING}

In order to demonstrate the effectiveness of the $8 \mathrm{~B} 10 \mathrm{~B}$ encoding scheme to relieve the ER requirements on the ASKmodulated payload, we have set-up the following transmission and label swapping experiment illustrated in Fig. 12. The packet generator consists of a DFB laser at $1550.9 \mathrm{~nm}$, a phase modulator, and two external dual-drive Mach-Zehnder modulators (MZMs). The DPSK label information at $2.5 \mathrm{~Gb} / \mathrm{s}$ (PRBS $2^{23}-1$ ) is added to the laser source by the phase modulator. The precoder circuit for the DPSK format is not applied in the experiment because the test signal is a PRBS pattern. The first MZM generates a 40-GHz return to zero (RZ) pulse train with $33 \%$ duty cycle. The modulator is biased at the peak of its transmission curve and differentially driven at twice the switching voltage with an ac-coupled half-bit-rate $(20-\mathrm{GHz})$ sine wave. The second MZM is driven by a $40-\mathrm{Gb} / \mathrm{s} 8 \mathrm{~B} 10 \mathrm{~B}-$ encoded data stream, thus producing an optically ASK/FSKlabeled signal. The initial ER of the payload is $12 \mathrm{~dB}$.

The transmission span consists of $40 \mathrm{~km}$ of standard SMF with a matching length of DCF in a postcompensation scheme. The dispersion of the SMF and DCF is 16.9 and $-100 \mathrm{ps} / \mathrm{nm} / \mathrm{km}$, respectively. After this transmission span, the optically labeled signal is inputted to a highly nonlinear fiber (HNLF) for wavelength conversion and label erasure. The wavelength converter is based on an optical Kerr switch. A tunable external cavity laser (ECL) at $1555.8 \mathrm{~nm}$ is used as a continuous wave $(\mathrm{CW})$ input for the Kerr switch. The labelerased payload then enters the phase modulator to get the new label. An optical add-drop multiplexer is used to extract the signal after transmission and label swapping. At the receiver, DPSK label demodulation is provided by an MZDI with 8 -cm delay length between its two arms. An LPF with $1.8-\mathrm{GHz}$ bandwidth is applied at the DPSK receiver to flatten the optical power distribution within one label bit and to remove the amplitude fluctuation induced by the intensity-modulated payload.

The detected eye diagrams for the $40 \mathrm{~Gb} / \mathrm{s}$ payload for the back-to-back case, transmission, and label updating are shown in Fig. 13(a)-(c), respectively. Fig. 13(d)-(f) shows the eye diagrams of the DPSK label. Very clear and open eyes can be obtained for both payload and label after transmission and label swapping. Because of the residual phase shift introduced by the Kerr switch, the payload ER after wavelength conversion is slightly degraded to $9 \mathrm{~dB}$ to ensure label detection. It is 


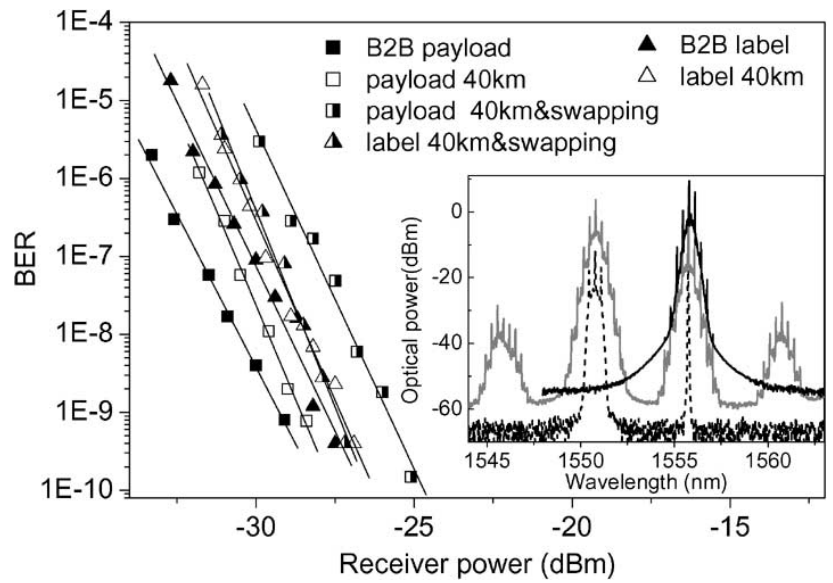

Fig. 14. Measured BER for payload and label in the back-to-back case, after $40 \mathrm{~km}$ transmission, and both after $40-\mathrm{km}$ transmission and label swapping. The inset shows the optical spectra at the HNLF input (dash line) and output (grey line), and for the label-swapped signal (solid black line).

envisaged that the ER degradation will limit the number of hops in multihop operation. To maintain signal quality after multihops, an ER maintaining wavelength converter or a $2 \mathrm{R}$ regenerator should be utilized in the label swapper.

Fig. 14 shows the bit error rate (BER) curves in the back-toback case, after transmission, and after the label swapper. The inset figure shows the optical spectra before and after wavelength conversion. The transmission penalties for the payload and label are less than $1 \mathrm{~dB}$. The label erasure and reinsertion result in 3.3-dB penalty to the payload compared to the backto-back case and $0.4-\mathrm{dB}$ penalty for the label.

\section{CONCLUSION}

The performance of ASK/DPSK labeling using a singleended receiver or a balanced receiver for DPSK label direct detection has been evaluated when the ASK payload is randomly coded. In both cases, an improvement in system performance was found for a lower bit rate DPSK label. This lower bit rate DPSK label, however, requires a stringent stabilization of the MZDI that will be a great challenge in practice. Therefore, the ER of the payload with random sequence must be limited in order to allow detection of the ASK/DPSK signal.

To increase the ER of the payload while simultaneously ensuring DPSK reception, $8 \mathrm{~B} 10 \mathrm{~B}$ coding is suggested for the payload. We compared the performance of a $40 \mathrm{~Gb} / \mathrm{s}$ ASK payload and a $2.5 \mathrm{~Gb} / \mathrm{s}$ or $622 \mathrm{Mb} / \mathrm{s}$ DPSK label with or without 8B10B coding. For the payload of PRBS $2^{7}-1$, the acceptable ER is only $7 \mathrm{~dB}$. By employing $8 \mathrm{~B} 10 \mathrm{~B}$ coding schemes on the payload, the acceptable ER can be increased up to $12 \mathrm{~dB}$. Finally, we demonstrated transmission over $40 \mathrm{~km} \mathrm{SMF}$ and optical label swapping for a $40 \mathrm{~Gb} / \mathrm{s} 8 \mathrm{~B} 10 \mathrm{~B}$ coded ASK payload and $2.5 \mathrm{~Gb} / \mathrm{s}$ DPSK label. The overall penalty of the payload is $3.3 \mathrm{~dB}$, and $0.3 \mathrm{~dB}$ for the label. The initial payload ER is $12 \mathrm{~dB}$. After transmission and label swapping, the ER is $9 \mathrm{~dB}$. This high ER of the high-speed payload demonstrates the scalability and transparency of future networks using optical ASK/DPSK label switching.

\section{REFERENCES}

[1] D. J. Blumenthal, B. E. Olsson, G. Rossi, T. E. Dimmick, L. Rau, M. Masanovic, O. Lavrova, R. Doshi, O. Jerphagnon, J. E. Bowers, V. Kaman, L. A. Coldren, and J. Barton, "All-optical label swapping networks and technologies," J. Lightw. Technol., vol. 18, no. 12, pp. 2058 2075, Dec. 2000.

[2] D. J. Blumenthal, A. Carena, L. Rau, V. Curri, and S. Humphries, "Alloptical label swapping with wavelength conversion for WDM-IP networks with subcarrier multiplexed addressing," IEEE Photon. Technol. Lett., vol. 11 , no. 11 , pp. 1497-1499, Nov. 1999.

[3] S. J. B. Yoo, H. Lee, Z. Pan, J. Cao, Z. Yanda, K. Okamoto, and S. Kamei, "Rapidly switching all-optical packet routing system with optical-label swapping incorporating tunable wavelength conversion and a uniformloss cyclic frequency AWGR," IEEE Photon. Technol. Lett., vol. 14, no. 8, pp. 1211-1213, Aug. 2002.

[4] A. Takada and J. H. Park, "Architecture of ultrafast optical packet switching ring network," J. Lightw. Technol., vol. 20, no. 12, pp. 2306-2315, Dec. 2002

[5] T. Koonen, G. Morthier, J. Jennen, H. Waardt, and P. Demeester, "Optical packet routing in IP-over-WDM networks deploying two-level optical labeling," presented at the Eur. Conf. Optical Communications (ECOC), Amsterdam, The Netherlands, 2001, Paper Th. L.2.1.

[6] T. Koonen, Sulur, I. Monroy, J. Jennen, and H. Waardt, "Optical labeling of packets in IP-over-WDM networks," presented at the Eur. Conf. Optical Communications (ECOC), Darmstadt, Germany, 2002, Paper 5.5.2.

[7] L. Xu, N. Chi, L. K. Oxenloewe, K. Yvind, J. Moerk, P. Jeppesen, and J. Hanberg, "Optical label encoding using electroabsorption modulators and investigation of chirp properties," J. Lightw. Technol., vol. 21, no. 8, pp. 1763-1769, Aug. 2003.

[8] N. Chi, B. Carlsson, P. V. Holm-Nielsen, C. Peucheret, and P. Jeppesen, "Dispersion management for two-level optically labeled signals in IPover-WDM networks," presented at the Eur. Conf. Optical Communications (ECOC), Copenhagen, Denmark, 2002, Paper 5.5.1.

[9] N. Chi, B. Carlsson, J. Zhang, P. V. Holm-Nielsen, C. Peucheret, and P. Jeppesen, "Transmission performance of all-optically labelled packets using ASK/DPSK orthogonal modulation," in Proc. Lasers and ElectroOptics Society (LEOS), Glasgow, U.K., 2002, vol. 1, pp. 51-53.

[10] N. Chi, J. Zhang, P. V. Holm-Nielsen, C. Peucheret, and P. Jeppesen, "Transmission and transparent wavelength conversion of an optically labelled signal using ASK/DPSK orthogonal modulation," IEEE Photon. Technol. Lett., vol. 15, no. 5, pp. 760-762, May 2003.

[11] J. Zhang, N. Chi, P. V. Holm-Nielsen, C. Peucheret, and P. Jeppesen, "10 Gb/s Manchester encoded FSK-labelled optical signal transmission link," Electron. Lett., vol. 39, no. 16, pp. 1193-1194, Aug. 2003.

[12] — " "An optical FSK transmitter based on an integrated DFB laser-EA modulator and its application in optical labeling," IEEE Photon. Technol. Lett., vol. 15, no. 7, pp. 984-986, Jul. 2003.

[13] M. Hickey and L. Kazovsky, "The STARNET coherent WDM computer communication network: Experimental transceiver employing a novel modulation format," J. Lightw. Technol., vol. 12, no. 5, pp. 876-884, May 1994.

[14] N. Chi, C. Mikkelsen, L. Xu, J. Zhang, P. V. Holm-Nielsen, H. Ou, J. Seoane, C. Peucheret, and P. Jeppesen, "Transmission and label encoding/erasure of an orthogonally labelled signal using a $40 \mathrm{~Gb} / \mathrm{s}$ RZ-DPSK payload and a $2.5 \mathrm{~Gb} / \mathrm{s}$ IM label," Electron. Lett., vol. 39 , no. 18 , pp. 1335-1337, Sep. 2003.

[15] X. Liu, Y. Su, X. Wei, J. Leuthold, and R. Giles, “Optical-label switching based on DPSK/ASK modulation format with balanced detection for DPSK payload," presented at the Eur. Conf. Optical Communications (ECOC), Rimini, Italy, 2003, Paper Tu4.4.3.

[16] N. Chi, L. Xu, J. Zhang, P. V. Holm-Nielsen, C. Peucheret, C. Mikkelsen, H. Ou, J. Seoane, and P. Jeppesen, "Orthogonal optical labeling based on a $40 \mathrm{~Gb} / \mathrm{s}$ DPSK payload and a $2.5 \mathrm{~Gb} / \mathrm{s}$ IM label," presented at the Optical Fiber Communication (OFC), Los Angels, CA, 2004, Paper FO6.

[17] N. Deng, Y. Yang, C. Chan, W. Hung, and L. Chen, "Intensity-modulated labeling and all-optical label swapping on angle-modulated optical packets," IEEE Photon. Technol. Lett., vol. 16, no. 4, pp. 1218-1220, Apr. 2004.

[18] M. C. Ho, C. L. Lu, R. T. Hofmeister, and L. G. Kazovsky, "Nonlinear cross-talk reduction by spectrum shaping in subcarrier signalling WDM networks," presented at the Conf. Lasers and Electro-Optics, San Francisco, CA, 1998, Paper CMG6.

[19] J. Zhang, P. V. Holm-Nielsen, N. Chi, C. Peucheret, and P. Jeppesen, "DC-balanced line encoding for optical labeling scheme using orthogonal modulation," presented at the Optical Fiber Communication (OFC), Los Angeles, CA, Feb. 2004, Paper WF2. 
[20] Y. Lin, M. C. Yuang, S. Lee, and W. Way, "Using superimposed ASK label in a $10 \mathrm{~Gb} / \mathrm{s}$ multihop all-optical label swapping system," J. Lightw. Technol., vol. 22, no. 2, pp. 351-353, Feb. 2004.

[21] W. Hung, C. Chan, and L. Chen, "A novel optical packet labeling scheme using interleaved low-speed DPSK labels," IEEE Photon. Technol. Lett., vol. 16, no. 2, pp. 698-700, Feb. 2004.

[22] G. J. Foschini, L. J. Greenstein, and G. Vannucci, "Noncoherent detection of coherent lightwave signals corrupted by phase noise," IEEE Trans. Commun., vol. 36, no. 3, pp. 306-314, Mar. 1988.

[23] A. X. Widmer and P. A. Franaszek, "A DC-balanced, partitionedblock, 8B/10B transmission code," IBM J. Res. Develop., vol. 27, no. 5, pp. 440-451, Sep. 1983.

[24] M. Hickey and L. Kazovsky, "Combined frequency and amplitude modulation for the STARNET WDM computer communication network," IEEE Photon. Technol. Lett., vol. 6, no. 12, pp. 1473-1475, Dec. 1994

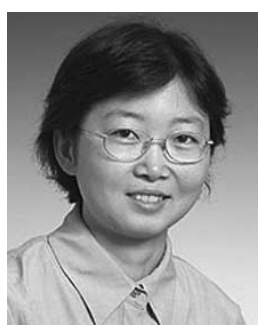

Nan Chi (M'03) was born in Liaoning, China, on March 3, 1974. She received the B.S. and Ph.D degrees in electrical engineering from Beijing University of Posts and Telecommunications, Beijing, China, in 1996 and 2001, respectively.

From July 2001 to December 2004, she was an assistant professor with the Research Center COM, Technical University of Denmark, Lyngby, Denmark. Since January 2005, she has been with the University of Bristol, Bristol, U.K. Her research interests are in the area of optical packet/burst switching, all-optical processing, and advanced modulation formats.

Lin Xu, photograph and biography not available at the time of publication.

Jianfeng Zhang (S'99-M'03), photograph and biography not available at the time of publication.

Pablo V. Holm-Nielsen, photograph and biography not available at the time of publication.

Christophe Peucheret, photograph and biography not available at the time of publication.

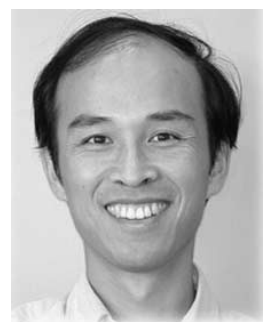

Siyuan Yu (M'05) was born in Nanchang, Jiangxi Province, China, in May 1963. He received the B.Eng. degree from Tsinghua University, Beijing, China, in 1984, the M.Eng. degree from Wuhan Research Institute of Post and Telecommunications, Wuhan, China, in 1987, where he worked on the frequency stabilization of semiconductor lasers, and the $\mathrm{Ph} . \mathrm{D}$. degree in electronics and electrical engineering from the University of Glasgow, Glasgow, U.K., in 1997, where he studied monolithically integrated mode-locked semiconductor ring lasers.

He joined the Department of Optoelectronic Engineering, Huazhong University of Science and Technology, in 1987, where he worked on semiconductor optical amplifiers and other optoelectronic devices. In 1996, he joined the Department of Electrical and Electronic Engineering, University of Bristol, Bristol, U.K., where he is currently a Senior Lecturer. His current research interests are photonic devices in optical networks, including optical packet switches, tunable lasers, wavelength converters, and all-optical switches. $\mathrm{He}$ is the author of more than 40 papers and inventor or co-inventor of one Chinese patent and four United Kingdom and international patents.

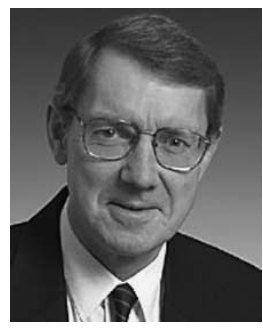

Palle Jeppesen (M'69) was born in Vordingborg, Denmark, on August 6, 1941. He received the M.Sc., Ph.D., and Dr.Sc. degrees in electrical engineering from the Technical University of Denmark, Lyngby, Denmark, in 1967, 1970 and 1978, respectively.

From 1968 to 1969, he was a Research Associate at Cornell University, Ithaca, NY, and from 1969 to 1970, he was a Project Engineer at Cayuga Associates, Ithaca; at both places, he did research in the field of GaAs Gunn-effect microwave oscillators. From 1970 to 1998, he was an Assistant, Associate, Research, and Full Professor at EMI, Technical University of Denmark, first in microwave electronics and, since 1974, in optical communications. At EMI, he was Head of the Optogroup from 1974 to 1988 and Head of the Center for Broadband Telecommunications from 1988 to 1998. From 1982 to 1984, he also worked as part-time Manager of R\&D at NKT Elektronik, now Draka Denmark Optical Cable, OFS Fitel Denmark, and Tellabs Denmark. From 1995 to 1998 , he coordinated the participation of the Technical University of Denmark in the EU ACTS project METropolitan Optical Network (METON). Since 1999, he has been Professor of optical communications at Research Center COM, Technical University of Denmark, where he is heading the Systems Competence Area. His current research interests are high-speed WDM optical communication systems, dispersion maps, WDM devices, and optical signal processing.

Dr. Jeppesen received the P. Gorm Petersens Memorial Stipend in 1974, the Esso Prize in 1978, and the Villum Kann Rasmussen Prize in 1988. He has been a member of the NATO Research and Technology Board since 1997 and of the NATO Science Committee since 1999. He was Chairman of European Conference on Optical Communication (ECOC) in 1981 and 2002. 